included a half-century of practice, from Laennec and Louis to Koch and Pasteur, who had seen the swifthanded surgery he was taught revolutionized by the discovery of ether, and who might have heard the then novel doctrine of the self-limitation of disease from the lips of its learned propounder. In his earlier days, to use his own words, "a doctor's call meant something. An emeto-cathartic inevitably followed the first visit, no matter what the disease might be." The doctor "was called to do something at once, and he generally did it." His " course was simple and easy. He had to be 'heroic' only with the lancet and heavy doses, and his responsibility was cancelled. If successful he had been lucky in hitting upon the right medicine; if unsuccessful, it was the patient's misfortune. ... But, alas for the cautious or unheroic practitioner. His failures were accounted no better than homicides, if not indictable." When a man of this training and experience, at the close of fifty years of practice, publicly suggests as a fitting and self-desired inscription for his tombstone, "He cured the sick without drugs," it has occurred to me that we might be justified in occasionally neglecting to do something.

Yes, I repeat, if by therapeutic nihilism is meant that we are mere lookers-on in Vienna, none of us will admit that such is an attitude we keep or desire. But if it is charged, that in the presence of disease we maintain at once a reasonable faith and an honest scepticism ; that we decline to fire at random and with all sorts of shot, in the childlike hope that Providence will kindly let us hit something; that, in short, we intend, as St. Paul advised the Thessalonians, to prove all things and hold fast that which is good,- then there are those among us, let us trust, who stand just there, unmoved by the ebb and flow of the tides of ignorance and prejudice. And why not? For, as Van Swieten said, a century and a half ago, in his Commentaries on the Aphorisms of Boërhaave, the learned professor of Leyden: "What will be the idea of the best Physician in future times we know not; but he is to be reckoned a good Physician now, who makes use of all the assistances by which, through the happiness of the present age, the art of Physick has been improved.'

\section{ETinital $\mathfrak{g}$ emorandum.}

\section{UNUSUAL SUSCEPTIBILITY TO SEDATIVE REMEDIES.}

BY ALBER'T N. BLODGETT, M.D.

Tue following case, which recently came under my observation, presented some features of peculiar interest, and I venture to record it :

The patient, a lady of twenty-four, in good health and free from any unusual teudencies, consulted me in relation to an acute neuralgia affecting the distribution of the facial nerve on the left side. Quinine in considerable doses, averaging ten grains a day for a few days, was sufficient to entirely relieve the distress, and the patient was for a time free from all disturbance.

The lady was in the fifth month of pregnancy, and again consulted me on account of a burning and smarting sensation following urination, which was very frequent, and occasioned much suffering from a constant pain in the back, hips, and at the orifice of the urethra. The patient stated that she had been for a time a guest at a well-known watering-place, and that many of the ladies there were affected in a similar manner, and that the general opinion had been formed that this was in some way due to the waters, although many of the guests had been formerly at the same place, and had never had occasion to complain of the action of the waters. 'The pain and distress were so severe that my patient left the place, and after some delay, in the hope that the trouble would spontaneously subside, consulted me, as above stated.

I made no local examination, but prescribed a solution of bicarbonate of soda, containing to each teaspoonful two grains of potass. brom. sodii. brom. and chloral hydrate, with the addition of one-twentiethgrain of morphia. 'This solution was prepared at six o'clock in the evening, and the patient took one teaspoonful at half-past six, one at half-past eight, one at 2 A. M., and one at $8 \mathrm{~A}$. M. She slept in the intervals, but awoke at the times stated, and, as she was alone, there is no other probable way in which the medicine could have been administered, except by her own hand. At eleven of the day, she rose and dressed and walked about her apartment, but feeling very drowsy and becoming rather frightened, she telegraphed for her husband, who came to her at four o'clock. She was at that time sleeping soundly, could with difficulty be wakened, and had no idea of the time, of her surroundings, or of the circumstances attending her condition. I was quickly summoned, and on reaching the patient found her dressed, seated in an arm-chair, and sleeping, with her head resting upon the back of a chair. Her color was good, there was no lividity of the skin, the breathing was easy, free, and natural, the pulse $7 \cdot 2$ and free, the skin a little cool, pupils dilated and sensitive, and the patient's condition was in no way otherwise changed from the appearances of ordinary healthy sleep. On trying to arouse her, there was no response to gentle measures, but by more vigorous methods she was sufficiently roused to open her eyes, to answer questions, and to give an account of her experiences. Two drops of the ordinary tincture of nux vomica were prepared in a little water, and the patient made to 8 wallow it. She was then forced to walk, and after a little time could stand, and was able to move by herself. On being left alone, she at once sank down without regard to her situation, and was immediately asleep, and had to be violently roused. About five minutes after taking the nux vomica there was a distinct tetanic convulsion of a moderate degree of intensity, which was not, however, repeated. She now began to show increased animation, and was soon able to go about unassisted, and at my advice was taken to walk in the open air. She had eaten nothing during the entire day, and after a half-hour was able to take a good dinner, and from this time was entirely free from any soporific influence.

'The patient said afterward that she had once before been similarly affected by a small amount of medicine given by a physician which contained bromides. She did not know the composition of the present mediciue, and had no idea that it contained these articles. 'There was no appearance of hysteria, and the case seems to be one of unusual susceptibility to the action of a class of drugs which are usually supposed to be comparatively mild in character, and to be safe in large doses. 